\title{
SOME CHARACTERISTICS OF AEROMONAS HYDROPHILA AND VIBRIO SPECIES ISOLATED FROM BACTERIAL DISEASE OUT- BREAKS IN ORNAMENTAL FISH CULTURE IN SRI LANKA
}

\author{
D.C. HETTLARACHCHI
}

Veterinary Diagnostic Laboratory, Ceylon Grain Elevators Limited, 15, Rockhouse

Lane, Colombo 15.

\section{C.H. CHEONG}

Ceylon Grain Elevators Limited, 15, Rockhouse Lane, Colombo 15.

(Received: 02 May 1994; accepted 06 November 1994)

\begin{abstract}
Bacterial fish disease outbreaks of freshwater ornamental fish hatcheries and farms, reported during the period from January, 1993 to February, 1994 in Sri Lanka were used in the study. Twelve fish species belonging to 11 genera were involved. Gross external and internal lesions were recorded. Samples were plated on selective (Aeromonas agar, Pseudomonas agar and thiosulfate citrate bile sucrose agar -TCBS) media and non-selective (blood agar and nutrient agar) media. Both API 20E and API GP test strips and conventional identification procedures were followed for characterization of the isolates. Following identification, 11 selected antibiotics were tested for their effectiveness against all the isolates using disk diffusion method. Aeromonas hydrophila was involved in $78.26 \%$ of the total (23) disease oútbreaks while Vibrio sp. was involved in the rest. Eroding fins, hemorrhagic lesions on the skin and at the base of tail fin, sloughing scales, hemorrhagic intestinal wall and other visceral organs were among the lesions observed due to A. hydrophila infection. Lesions observed due to vibriosis were, erratic swimming, hemorrhagic patches on skin and on areas around anus, base of pelvic and tail fins, hemorrhagic peritoneum and visceral organs, fluid filled erythemic intestine and blindness among some survivors. All isolates of $A$. hydrophila were resistant to the tested antibiotics of the families tetracycline and penicillin, and trimethoprim, trimethoprim+sulfamethoxazol and streptomycin. Antibiotics of the family quinolones (norfloxacin and flumequine), nitrofurantoin and gentamicin proved to be the most efficacious on $A$. hydrophila isolates. All Vibrio sp. isolates were sensitive to 11 antibiotics tested except colistin and streptomycin.
\end{abstract}

Key words: Aeromonas, antibiotics, bacterial diseases, fish, Vibrio

\section{INTRODUCTION}

As the global ornamental fish trade has been growing steadily over the years, the number of hatcheries, farms and trade agencies has increased markedly over the last decade. In 1988, the global value of the aquarium industry was estimated at US $\$ 4$ billion. ${ }^{1}$ Singapore, the world's largest exporter of tropical fish, earned US $\$ 38$ million from this trade in 1988 while Sri Lanka which earned slightly over US $\$ 1$ million in 1985 doubled its export in 1988 and has been projected to earn US $\$ 4$ million in 1994 from this industry. ${ }^{1,2}$ Although the industry has been growing, almost all farmers experience setbacks in production during larval rearing, growout and transportation especially due to high mortality associated with diseases and related disorders which estimates roughly to about $40 \%$ of the total production. ${ }^{1}$ 
It is well established in ornamental fish industry that bacterial infections are responsible for heavy losses from the farm level to the hobbyist tank. Gratzek et $a l^{3}$ and Shotts et al. ${ }^{4}$ established that $15 \%$ of the 73 bags of pet fish originating from Southeast Asia had Aeromonas hydrophila. However, literature on bacterial diseases of ornamental fish culture in Sri Lanka is scarce. ${ }^{5}$

This work was therefore undertaken to investigate the bacterial disease outbreaks in ornamental fish culture in Sri Lanka, characterize the pathogens and to determine the sensitivity of the bacteria involved to commonly used antibiotics with a view to provide the farmers with the information on effective treatment.

\section{METHODS AND MATERIALS}

Bacterial diseases of freshwater ornamental fish that were reported to our laboratory from hatcheries and farms during the period January,1993 to February, 1994 were investigated.

Selection of specimens: The fish species involved were: Zebrafish (Brachydanio rerio), Penguinfi'sh (Thayeria boehlhei), Black Widow (Gymnocorymbusternetzi), Super Serpae (Hyphessobrycon callistus callistus), Cuming's Barb (Puntius cumingi), Cherry Barb (Puntius titteya), Angelfish (Pterophyllum scalare), Guppies (Poecillia reticulata), Red Swordtail (Xiphophorus helleri), Kissing Gourami (Helostoma temmincki), Goldfish (Carassius auratus) and Giant Gourami (Osphromenus gorami). Only affected live or moribund fish were selected for the study.

Physical examination: Fish were examined for the presence of external and internal parasites and macroscopic lesions were recorded. Samples for bacteriological culture were taken directly from lesions as well as from liver, kidney, peritonial cavity and intestinal contents aseptically. When fry and juveniles were involved, sampling was done according to Tanasomwang and Muroga ${ }^{6}$ and direct plating was carried out with the homogenate.

Media and culture techniques: Primary isolation of bacteria was carried out on Pseudomonas agar, Aeromonas agar,thiosulfate citrate bile sucrose agar,blood agar and nutrient agar (Oxoid, England). Plates were incubated at room temperature $\left(26^{\circ} \mathrm{C}\right)$ for 24 to $48 \mathrm{~h}$ and predominant colonies, both from selective and non-selective media were subcultured and purified on nutrient agar. One such pure culture was taken from each outbreak of disease.

Identification of bacteria: The cultures were identified using miniaturized biochemical tests of API 20E and API GP (Analytab Product, Plainview,England) with species identification of Aeromonas and confirmed by biochemical tests according to Frerichs. ${ }^{7}$ Characteristics of Vibrio sp. were compared with those of the isolate of Pena et al. ${ }^{8}$ 
ABST: The isolates were subjected to antibiotic sensitivity tests using susceptibility disks with the standard disk diffusion method on PDM antibiotic sensitivity medium (AB BIODISK, Solna,Sweden). Following incubation at room temperature $\left(26^{\circ} \mathrm{C}\right)$ for $24 \mathrm{~h}$, inhibition zones were measured and the bacteria were classified as resistant and sensitive. Susceptibility disks used

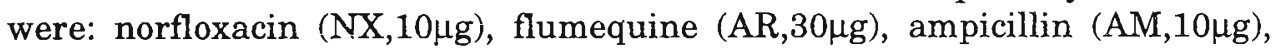
tetracycline $(\mathrm{TC}, 30 \mu \mathrm{g})$, chloramphenicol $(\mathrm{CL}, 30 \mu \mathrm{g})$, nitrofurantoin (NI,100 $\mu \mathrm{g})$,

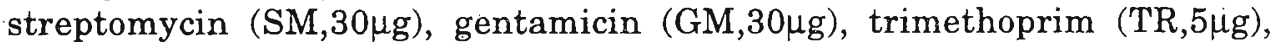
trimethoprim + sulfamethoxazol $(\mathrm{TS}, 1.2 \mu \mathrm{g}+23.8 \mu \mathrm{g})$ and colistin $(\mathrm{CO}, 30 \mu \mathrm{g})$.

\section{RESULTS}

Aeromonas hydrophila was the most dominant isolate in 18 outbreaks out of the 23 cases investigated. The fish involved in these outbreaks were: Goldfish juveniles and adults, Kissing gourami fry, Angelfish juveniles, Giant gourami, Zebrafish; Guppies, Super serpae, Swordtail, Cuming's barb, and Cherry barb. Eroding fins, sloughing scales, hemorrhagic skin, intestine and other visceral organs, ulcerative necrosis at the base of tail fin were among the lesions observed due to A.hydrophila infections.

The dominant isolate in the other five disease outbreaks was Vibrio sp. in which Swordtail, Black widow fish, Super serpae, Penguinfish, Angelfish, and Cherry barb were involved. Lesions observed due to vibriosis were, erratic swimming, hemorrhagic peritoneum and visceral organs, fluid filled erythemic intestine and blindness among some survivors.

Table 1: Inconsistent cultural and biochemical characteristics of Aeromonas hydrophila isolated from freshwater ornamental fish during disease outbreaks from Jan.,1993 to Feb.,1994. ( $n=18$ ).

\begin{tabular}{lc}
\hline \multicolumn{1}{c}{ Test } & Reaction* \\
\hline Citrate utilization & $-(66.7 \%)$ \\
Voges Proskauer & $+(77.8 \%)$ \\
Lysine decarboxylase & $+(50.0 \%)$ \\
Acid from L+arabinose & $-(88.9 \%)$ \\
Acid from inositol & $-(94.4 \%)$ \\
Acid from salicin & $+(50.0 \%)$ \\
Acid from rhamnose & $-(94.4 \%)$ \\
Acid from sorbitol & $+(89.0 \%)$ \\
Acid from melibiose & $+(61.1 \%)$ \\
Acid from amygdalin & $+(72.2 \%)$ \\
\hline
\end{tabular}

* Percentage of isolates showing given reactions.

Many of the cultural and biochemical characteristics of A.hydrophila isolated from the disease outbreaks were consistent while some varied among the isolates. Those inconsistent characters are shown in Table 1. Vibrio sp. isolated 
showed growth characteristics of 1-2 mm, low convex; circular colonies on blood agar (after $24 \mathrm{~h}$ at $26^{\circ} \mathrm{C}$ ), less than $1 \mathrm{~mm}$ light green colonies on TCBS agar after $24 \mathrm{~h}$ which turned white $(2 \mathrm{~mm})$ with a large yellow surrounding after $48 \mathrm{~h}$. The 5 Vibrio sp. isolated showed almost the same characteristics except for reactions in Voges-Proskauer and salt requirement as shown in Tables 2 and 3. For comparison, the characteristics of the Vibrio sp. reported ${ }^{8}$ as the causative agent of vibriosis in the Kuruma prawn are presented in these tables. All A. hydrophila isolates were sensitive to $\mathrm{NX}, \mathrm{AR}, \mathrm{GM}$, and $\mathrm{NI}$ and resistant to $\mathrm{AM}$ and TC. Twenty seven percent were resistant to CL, $11.70 \%$ were resistant to TM and TS. The Vibrio sp. were sensitive to the tested antibiotics except CO,NI and SM. The percentage sensitivity of $A$. hydrophila and Vibrio sp. to the antibiotics are shown in Tables 4 and 5.

Table 2: Cultural and biochemical characteristics of Vibrio sp. isolated from freshwater ornamental fish during disease outbreaks from Jan., 1993 to Feb., $1994(n=5)$.

\section{Test/characteristic}

Vibrio sp.

Present isolate

Mortality

Shape

Swarming

Oxidase

Catalase

Hugh-Leifson's (OF)

Gas from glucose

Nitrate reduction

Voges Proskauer

Indole

Hydrogen sulfide

Citrate (Simmon's)

Beta-galactosidase

Arginine decarboxylase

Lysine decarboxylase

Ornithine decarboxylase

Gelatine liquefaction

Sensitivity to $0 / 129$

Growth at $4^{\circ} \mathrm{C}$

$$
37^{\circ} \mathrm{C}
$$

$40^{\circ} \mathrm{C}$

Growth in peptone water

$\begin{array}{ll}0 \% & \mathrm{NaCl} \\ 0.5 \% & \mathrm{NaCl} \\ 3 \% & \mathrm{NaCl} \\ 6 \% & \mathrm{NaCl}\end{array}$

Vibrio sp.

Pena et al. ${ }^{8}$ 
Table 3: Carbohydrate utilization of Vibrio sp. isolated from freshwater ornamental fish during disease outbreaks from Jan.,1993 to Feb.,1994 $(\mathbf{n}=\mathbf{5})$.

Characteristic

Vibrio sp.

Present isolate
Vibrio sp.

Pena et al. ${ }^{8}$

Acid from:

Arabinose

Esculin

Glucose

Glycerol

Inositol

Mannitol

Mannose

Melibiose

Raffinose

Rhamnose

Salicin

Sorbitol

Sucrose

Starch

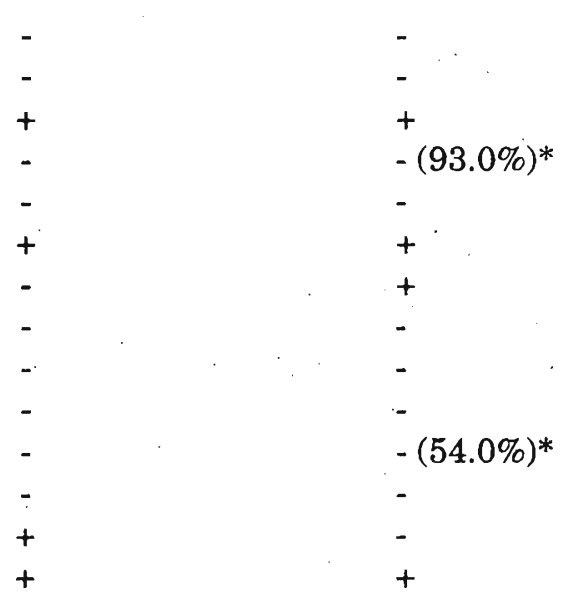

- Percentage of isolates showing given reactions.

Table 4 : Antibiotic sensitivity of Aeromonas hydrophila isolated from freshwater ornamental fish during disease outbreaks from Jan.,1993 to Feb.,1994 (n = 18).

\begin{tabular}{lcc}
\hline Antibiotic & \multicolumn{2}{c}{ Percentage sensitivity (\%) } \\
\cline { 2 - 3 } & Sensitive & Resistant \\
\hline Norfloxacin & 100.0 & - \\
Flumequine & 100.0 & - \\
Ampicillin & - & 100.0 \\
Tetracycline & - & 100.0 \\
Chloramphenicol & 72.2 & 27.8 \\
Nitrofurantoin & 100.0 & - \\
Streptomycin & - & 100.0 \\
Gentamicin & 100.0 & - \\
Trimethoprim & 11.7 & 88.3 \\
Trimethoprim+Sulfamethoxazol & 11.7 & 88.3 \\
\end{tabular}


Table 5 : Antibiotic sensitivity of Vibrio sp. isolated from freshwater ornamental fish during disease outbreaks from Jan., 1993 to Feb., 1994 $(\mathbf{n}=\mathbf{5})$.

\begin{tabular}{lcc}
\hline Antibiotic & Reaction & \\
& Sensitive & Resistant \\
\hline Norfloxacin & $5 / 5^{*}$ & - \\
Flumequine & $5 / 5$ & - \\
Ampicillin & $5 / 5$ & - \\
Tetracycline & $5 / 5$ & - \\
Chloramphenicol & $5 / 5$ & - \\
Colistin & - & $5 / 5^{*}$ \\
Nitrofurantoin & $3 / 5$ & $2 / 5$ \\
Streptomycin & $2 / 5$ & $3 / 5$ \\
Gentamicin & $5 / 5$ & - \\
Trimethoprim & $5 / 5$ & - \\
Trimethoprim+Sulfamethoxazol & $5 / 5$ & - \\
\hline
\end{tabular}

- Number of isolates showing given reactions/total isolates tested.

\section{DISCUSSION}

Aeromonas hydrophila was involved in $78.26 \%$ of the total (23) bacterial disease outbreaks investigated during the study period. This, an opportunistic pathogen was reported to be the predominant pathogen found in lesions of Epizootic Ulcerative Syndrome (EUS) affected fish ${ }^{9,10,11 .}$ Costa and Wijeyaratne, ${ }^{12}$ Subasinghe et al. ${ }^{9}$, Pathiratne et al..$^{13}$ reported that over 21 species of brackish and freshwater fish in Sri Lanka were affected by EUS. EUSlesions (hemorrhages and ulcerative necrosis in the skin on various parts of the body) were observed in the present study on A. hydrophila affected fish except larvae of Kissing Gourami and juveniles of Angelfish. Dixon et al. ${ }^{14}$ found that about $43 \%$ of the Aeromonas isolates from a variety of tropical pet fish imported from Singapore were A. hydrophila which were causing monomicrobial infections in these fish. Shotts et al. ${ }^{4}$ also established A. hydrophila as a major disease problem in ornamental fish. These and the results of the present study demonstrate the potential of $A$. hydrophila as a serious pathogen in ornamental fish industry.

A. hydrophila isolated in the present study were resistant to TC. This finding is in agreement with the observation of Dixon et al. ${ }^{14}$, Supriyadi and Rukyani. ${ }^{15}$ In the present study, $27.77 \%$ of the Aeromonas isolates showed multiple resistant to TC and CL. This is comparable with the observations made by Aoki and Watanabe ${ }^{16}$ who isolated multiple drug resistant (to TC and CL) A. hydrophila from freshwater fish in Thailand. Of the antibiotics tested, GM,AR, and NX were the most efficacious on A. hydrophila isolates. Dixon et al. ${ }^{14}$ also found the quinolone family antibiotics as the most effective antimicrobial drug on freshwater A. hydrophila from ornamental fish. Though the development of plasmid mediated resistant to quinolones is rare, ${ }^{17}$ Supryadi and 
Rukyani ${ }^{15}$ noted that $70 \%$ of the thirty $A$. hydrophila isolates from affected freshwater fish were resistant to $\mathrm{AR}$ in Indonesia.

The Vibrio sp. isolated from the five disease outbreaks were categorized as belonging to species. Most of the characteristics of these isolates coincide with those of the Vibrio sp. reported by Pena et al. ${ }^{8}$ from diseased Kuruma prawn, Penaeus japonicus. However, the true freshwater character of the present isolates was well supported by their ability to grow in salt level as low as $0.5 \%$.

Internal and external lesions of the disease caused by this bacteria were similar to those of vibriosis described by Post. ${ }^{18}$ Vibriosis'of freshwater fish has not been recorded earlier in Sri Lanka. The list of susceptible freshwater fish species to vibriosis by Post $^{18}$ did not.include any of the species involved in the present outbreaks of vibriosis.

All five Vibrio sp. isolated were sensitive to the eleven antibiotics tested except CO, NI and SM. In contrast, many authors reported resistant Vibrio sp. to commonly used antibiotics from marine environments. ${ }^{19.20,21}$

In conclusion, this investigation provides valuable information to the farmers on the two major bacterial killers of freshwater ornamental fish in Sri Lanka and a choice of the most effective antimicrobials against them. This also provides information for the scientists on the emergence of vibriosis of freshwater fish which has not been recorded earlier in this country.

\section{Acknowledgement}

We express our gratitude to Prof. M.J.S.Wijeyaratne and Dr. M.Hettiarachchi of the Department of Zoology,University of Kelaniya for reviewing the manuscript.

\section{Reference}

1. Shariff M. \& Subasinghe R.P. (1992). Aquarium fish health - do we really care ? INFOFISH International 6: 43-47.

2. Anonymous (1989). National Fisheries Development Plan 1990-1994, Ministry of Fisheries and Aquaculture Resources, Sri Lanka.

3. Gratzek J.B., Shotts E.B., \& Blue J.L. (1978). Ornamental fish: diseases and problems. United States National Marine Fisheries Service Marine Fisheries Review 40 (3): 58-60.

4. Shotts E.B., Kleckner A.L., Gratzek J.B., \& Blue J.L. (1976). Bacterial flora of aquarium fishes and their shipping waters imported from Southeast Asia. Journal of the Fisheries Research Board of Canada 33: 732-735. 
5. Subasinghe R.P. (1992). Hatchery diseases of freshwater fish in Sri Lanka. In: Diseases in Asian Aquaculture (I) (Eds. M. Shariff, R.P. Subasinghe and J.R. Arthur), p. 209-214. Fish Health Section, Asian Fisheries Society, Manila, Philippines.

6. Tanasomwang V., \& Muroga K. (1990). Intestinal microflora of marine fishes at their larval and juvenile stages. In: The Second Asian Fisheries Forum (Eds. R.Hirano and I. Hanyu) pp. 647-650. Asian Fisheries Society, Manila, Philippines.

7. Frerichs G. (1984). The isolation and identification of fish bacterial pathogens. Institute of Aquaculture, University of Sterling, Scotland.

8. Pena De La L.D.,Takahiro T, Kazuo, M.,Toshihiro N. \& Muroga K. (1993). Characteristics of the causative bacterium of vibriosis in kuruma prawn, Penaeus japonicus. Aquaculture 115 : 1-12.

9. Subasinghe R.P., Jayasinghe L.P., Balasuriya K.S.W. \& Kulathilaka M. (1990). Preliminary investigations into the bacterial and fungal pathogens associated with the Ulcerative Fish Disease Syndrome in Sri Lanka. In: The Second Asian Fisheries Forum. (Eds.R.Hirano and I. Hanyu) pp. 665-666. Asian Fisheries Society, Manila, Philippines.

10. Torres L.J., .Shariff M. \& Law A.T. (1990). Identification and virulence screening of Aeromonas spp. isolated from healthy and Epizootic Ulcerative Syndrome (EUS) - infected fish. In: The Second Asian Fisheries Forum. (Eds.R.Hirano and I.Hanyu) pp. 663-666. Asian Fisheries Society, Manila, Philippines.

11. Lilley J.H., Philliphs M.J. \& Tonguthai K. (1992). A review of Epizootic Ulcerative Syndrome (EUS) in Asia. p. 173. Aquatic Animal Health Research Institute and Network of Aquaculture Centres in Asia-Pacific, Bangkok.

12. Costa H.H. \& Wijeyaratne M.J.S. (1989). Epidemiology of the Epizootic Ulcerative Syndrome occurring for the first time among fish in Sri Lanka. Journal of Applied Ichthyology 1:48-52.

13. Pathiratne A., Widanapathirana G.S. \& Chandrakanthi W.H.S. Aeromonas hydrophila, the bacterial pathogen associated with Epizootic Ulcerative Syndrome (EUS) of freshwater fish in Sri Lanka. Journal of Applied Ichthyology (1995). In press.

14. Dixon B.A., Yamashita J. \& Evelyn F.(1990). Antibioticresistance of Aeromonas spp. isolated from tropical fish imported from Singapore. Journal of Aquatic Animal Health 2: 295-297. 
15. Supriyadi H., \& Rukyani A. (1992). The use of chemotherapeutic agents for the treatment of bacterial diseases of fish and shrimps in Indonesia. In: Diseases in Asian Aquaculture (I) (Eds. M. Shariff, R.P. Subasinghe and J.R. Arthur) pp. 515-517. Fish Health Section, Asian Fisheries Society, Manila, Philippines.

16. Aoki T., Watanabe T. (1973). Studies of drug resistant bacteria from eelpond water and intestinal tracts of the eel (Anguilla japonica and Anguilla anguilla). Bulletin Japanese Society Scientific Fisheries 39: 938-942.

17. Fraser M., Bergeron J.A. Mays A. \& Aiello S.E. (1991). The Merck Veterinary Manual. A handbook of diagnosis, therapy and disease prevention and control for the veterinarian. 7th ed. Merck \& Co., New Jersey.

18. Post G. (1983). Textbook of Fish Health. TFH Publications, Neptune, New Jersey.

19. Nash G., Nithimathachoke C., Tungmandi C., ArkarjamornA., Prathanpipat P. \& Ruamthaveesub P. (1992). Vibriosis and its control in pond-reared Penaeus monodon in Thailand. In: Diseases in Asian Aquaculture, (I). (Eds. M.Shariff, R.P. Subasinghe and J.R.Arthur) pp.143-155. Fish Health Section, Asian Fisheries Society, Manila, Philippines.

20. Baticados M.C.L., \& Paclibare J.O. (1992). The use of chemotherapeutic agents in aquaculture in Philippines. In: Diseases in Asian Aquaculture, (I) (Eds.M.Shariff, R.P. Subasinghe and J.R. Arthur) pp. 531-546. Fish Health Section, Asian Fisheries Society, Manila, Philippines.

21. Toranzo A.E. et al. (1993). Microflora associated with healthy and diseased turbot (Scopthalmus maximus) from three farms in Northwest Spain. Aquaculture 114: 189-202. 